\title{
Human footprint defining conservation strategies in Patagonian landscapes: Where we are and where we want to go?
}

\author{
Yamina Micaela Rosas ${ }^{\mathrm{a}, *}$, Pablo L. Peri ${ }^{\mathrm{b}}$, Anna M. Pidgeon ${ }^{\mathrm{c}}$, Natalia Politi ${ }^{\mathrm{d}}$, Julieta Pedrana ${ }^{\mathrm{e}}$, \\ Ricardo Díaz-Delgado ${ }^{\mathrm{f}}$, Guillermo Martínez Pastur ${ }^{\mathrm{a}}$ \\ ${ }^{a}$ Laboratorio de Recursos Agroforestales, Centro Austral de Investigaciones Científicas (CADIC), Consejo Nacional de Investigaciones Científicas y Técnicas (CONICET), \\ Houssay 200 (9410) Ushuaia, Tierra del Fuego, Argentina \\ ${ }^{\mathrm{b}}$ Instituto Nacional de Tecnología Agropecuaria (INTA), Universidad Nacional de la Patagonia Austral (UNPA), Consejo Nacional de Investigaciones Científicas y \\ Técnicas (CONICET), CC 332 (9400) Río Gallegos, Santa Cruz, Argentina \\ c SILVIS Lab, University of Wisconsin-Madison, Department of Forest and Wildlife Ecology, Linden Drive 1630 (53706), Madison, WI, USA \\ ${ }^{\mathrm{d}}$ Facultad de Ciencias Agrarias, Universidad Nacional de Jujuy, Consejo Nacional de Investigaciones Científicas y Técnicas (CONICET), Juan Bautista Alberdi 47 \\ (Y4600DTA), Jujuy, Argentina \\ ${ }^{\mathrm{e}}$ Instituto Nacional de Tecnología Agropecuaria (INTA), Ruta 226 Km 73,5 (7620) Balcarce, Buenos Aires, Argentina \\ ${ }^{\mathrm{f}}$ Laboratorio de SIG y Teledetección, Estación Biológica de Doñana (CSIC), Cartuja TA-10, Edificio I, Calla Américo Vespucio s/n (41092), Sevilla, Spain
}

\section{A R T I C L E I N F O}

\section{Keywords:}

Wilderness

Forested landscapes

Drivers of change

Human impact

Conservation

Landscape scale

\begin{abstract}
A B S T R A C T
Understanding human influence on ecosystems and their services is crucial to achieve sustainable development and ensure the conservation of biodiversity. In this context, the human footprint index (HFI) represents the anthropogenic impacts on ecosystems and the natural environment. Our objective was to characterize the HFI in Southern Patagonia (Argentina) across the landscape, qualifying the differences among the main ecological areas and especially the forested landscapes. We also assessed the potential utility of HFI to identify priority conservation areas according to their wilderness quality and potential biodiversity values. We created a HFI map (scores varied from 0 representing high wilderness quality to 1 representing maximum human impact) using variables related to direct (e.g. infrastructure) and indirect (e.g. derived from economic activities) human impacts, including settlements, accessibility, oil industry, and sheep production. HFI varied significantly across the natural landscapes, being lower $(0.07-0.11)$ in remote ecosystems close to the Andes Mountains and higher $(0.38-0.40)$ in southern areas close to the provincial capital city. Forested landscapes presented different impact values, which were directly related to the economical values of the different forest types. We determined that the current protected area network is not equally distributed across the different ecological areas and forest types. Priority conservation areas were also identified using the fragmentation produced by the human impact, the patch size, and the potential biodiversity values. HFI can present high compatibility with other land-use management decision making tools, acting as a complement to the existing tools for conservation planning or management.
\end{abstract}

\section{Introduction}

Human influence is one of the most important factors affecting life in the world (Jacobson, Riggio, Tait, \& Baillie, 2019; Mace, Balmford, \& Ginsberg, 1998), which is currently in a new geological era, the Anthropocene (Corlett, 2015; Sanderson et al., 2002). The transformation of ecosystems by humans has resulted in declines of wilderness areas, loss of biodiversity, and degradation of several ecosystem services (Myers, Mittermeier, Mittermeier, Da Fonseca, \& Kent, 2000; de Groot et al., 2012; Watson et al., 2016; Li, Zhang, Wang, \& Li, 2018). In this context, the understanding of the human impact on ecosystems, and the services that they provide, is crucial to achieve sustainable development (Costanza et al., 2017). Global maps of land use changes and cover (Hansen et al., 2013; Loveland et al., 2000) in combination with large datasets related to human economic activities across the world, and the advances in geographic information systems (GIS), provide the

\footnotetext{
* Corresponding author.

E-mail addresses: micaela.rosas@cadic-conicet.gob.ar (Y.M. Rosas), peri.pablo@inta.gob.ar (P.L. Peri), apidgeon@wisc.edu (A.M. Pidgeon), natalia.politi@ fulbrightmail.org (N. Politi), jpedrana@gmail.com (J. Pedrana), rdiaz@ebd.csic.es (R. Díaz-Delgado), gpastur@conicet.gov.ar (G.M. Pastur).
} 
integration technology necessary to combine these data in an efficient and reproducible manner (McGowan, 2016; Sanderson et al., 2002) and are important tools to determine the influence of humans on earth (Sanderson et al., 2002), even in areas with low data availability such as Southern Patagonia (Martínez Pastur, Peri, Lencinas, García Llorente, \& Martín López, 2016).

The human footprint index (HFI) has been used to represent the continuum of anthropogenic impacts on the environment (Sanderson et al., 2002). HFI defines human influence using geographic proxies from four data types: population density, land transformation, accessibility, and electrical power infrastructure (Venter et al., 2016). These data must be selected according to their coverage, consistency and relevance for characterizing human impact on the environment (Sanderson et al., 2002). However, global scale datasets (e.g. Sanderson et al., 2002) are often too coarse for regional analyses to be useful to managers or policy makers (Li et al., 2018; Woolmer et al., 2008). Therefore, studies of human influence using locally developed data at finer scales are a solution to this problem (e.g. Inostroza, Zasada, \& König, 2016; Correa Ayram, Mendoza, Etter, \& Perez Salicrup, 2017; Li et al., 2018; Pertierra, Hughes, Vega, \& Olalla-Tárraga, 2017; Martinuzzi et al., 2018). Using local data, the HFI becomes a powerful tool for land use planning for conservation (Li et al., 2018; Pertierra et al., 2017), assessing extinction risk (Di Marco, Venter, Possingham, \& Watson, 2018), habitat connectivity (Correa Ayram et al., 2017), multi-scaled adaptive monitoring (Burton et al., 2014), and also for infrastructure design for human health and well-being (Baldwin, Powell, \& Kellert, 2011).

Southern Patagonia includes landscapes with extreme environmental conditions, from arid steppes to dense temperate forests (Peri et al., 2016), and with varying levels of naturalness and human impacts (e.g. from pristine to severely degraded by livestock grazing or desertification) that can greatly affect local biodiversity (Rosas, Peri, Lencinas, \& Martínez Pastur, 2019; Rosas, Peri, \& Martínez Pastur, 2018; Rosas, Peri, Carrara et al., 2019). Many areas in Southern Patagonia with the least amount of human influence are of outstanding global value for the conservation of endemic natural features, species, and unique biodiversity (Inostroza et al., 2016). However these environments and the ecosystem services that they provide are vulnerable to human disturbances and climate change (Peri, Rosas et al., 2019). To support sustainable land-use and conservation policies, especially for remaining wilderness areas in Southern Patagonia requires data that incorporates regional details, developed at a resolution relevant to policy making (Peri et al., 2016; Rosas, Peri, Carrara et al., 2019, Rosas, Peri, Lencinas et al., 2019).

Sanderson et al. (2002) identified the last $10 \%$ wildest areas in each biome in the world for biodiversity conservation (from 5 to 100,000 $\mathrm{km}^{2}$ ). The use of HFI may assist in defining areas for conservation along the continuum of human influence (Li et al., 2018; Sanderson et al., 2002), because because HFI can quantify fragmentation of natural landscapes which can serve as a proxy for biodiversity conservation (Jacobson et al., 2019). Jacobson et al (2019) proposed that the HFI is approximately the inverse of the geography of natural processes and patterns, assuming that where human influence is highest, ecosystems are more modified and biodiversity is under the greatest pressure from human activity. Humans exert pressures on the planet in a great many ways that may lead directly or indirectly to changes in natural systems (McGowan, 2016). The rationale behind this methodology is that more intense human footprint represents less value for conservation due to biodiversity loss, habitat degradation, exotic species invasion, contamination and trade-offs between natural values and human economic activities (e.g. livestock grazing) (Di Marco et al., 2018; Li et al., 2018; Venter et al., 2016). The objective of this work was to characterize the HFI for Southern Patagonia of Argentina considering different ecological areas and different forested landscapes, and to identify areas of high conservation value according to their degree of wilderness, which we define as lack of human influence. Particularly, we aimed to: (1) include regionally-specific indirect human variables in our HFI, (2) characterize the HFI within different ecosystems and forested landscapes, and to (3) identify remaining wilderness areas. Finally, combining information about fragmentation measures with the HFI, we aimed to (4) propose new areas for conservation as protected areas from the set of the most wild, and most ecologically sensitive land cover patches identified in our analysis.

\section{Methods}

We developed a map of the human footprint index (HFI) for Santa Cruz province (Argentina) $\left(46^{\circ} 00^{\prime}\right.$ to $52^{\circ} 30^{\prime} \mathrm{S}, 66^{\circ} 00^{\prime}$ to $73^{\circ} 00^{\prime} \mathrm{W}$ ) based on the methodology proposed by Sanderson et al. (2002) but incorporating regional variables. Santa Cruz province covers 243,943 $\mathrm{km}^{2}$ (Fig. 1A) and includes 273,000 inhabitants (1.38 inhab $\mathrm{km}^{-2}$ ), who live in Rio Gallegos, the provincial capital ( $>90,000$ people), other cities (e.g. Caleta Olivia and El Chaltén with $>1000$ people), small towns (e.g. Cañadón Seco and Fitz Roy with $<1000$ people), and on more than 1100 sheep ranches across the province. The accessibility in the area is limited, with three national routes that mainly cross from north to south and provincial routes that connect the main human settlements. Oil extraction is one of the most important economic activities, and infrastructure includes wells and pipelines. Another important local industry revolves around sheep production (lamb meat and wool), and and grazing affects natural grasslands and shrublands, with higher stocking rates in southern areas of the province (Pedrana, Bustamante,

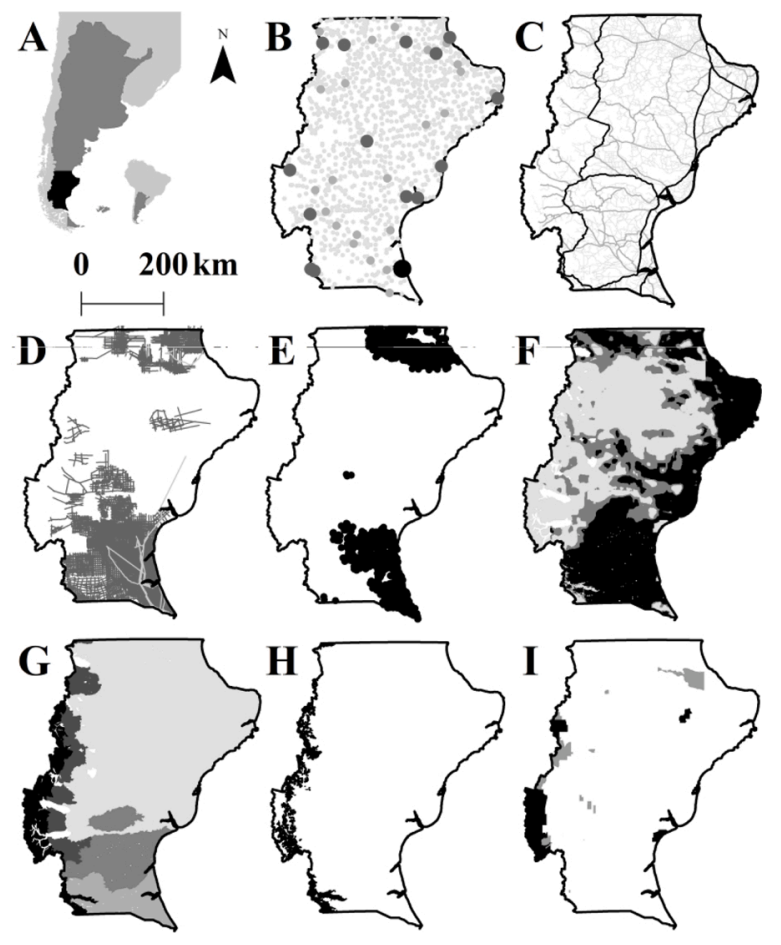

Fig. 1. Characterization of the study area: (A) location of South America (grey), Argentina (dark grey) and Santa Cruz province (black); (B) human settlements (black dot $=$ capital city, big dark grey dots $=>1000$ inhabitants, medium grey dots $=<1000$ inhabitants, little light grey dots = ranches); (C) accessibility (black $=$ national routes, grey $=$ provincial routes, light grey $=$ secondary roads and trails); (D) oil industry (grey = oil exploration lines, light grey = pipelines); (E) oil wells (black dots); (F) sheep grazing impact (light grey = low, grey = medium, black = high) (modified from Pedrana et al., 2011); (G) main ecological areas (light grey = dry steppe, grey = humid steppe, medium grey = shrub-lands, dark grey $=$ sub-Andean grasslands, black $=$ forests and alpine vegetation) (modified from Oliva et al., 2004); (H) distribution of Nothofagus forests; and (i) protected areas (grey = provincial reserves, black = national parks). 
Rodríguez, \& Travaini, 2011).

Mapping the HFI requires a series of steps: (A) identification of the variables, (B) application of impact scores, and (C) combination of the different variables in a single map. For the first step (A), we constructed a database with variables related to human impact as proxies for HFI, both direct (e.g. infrastructure) and indirect (e.g. livestock) at landscape level (Appendix A in Supplementary Material). The landscape impact variables (LIV) used in this study were: (i) human settlements $(n=4$ types) defined by size (Fig. 1B); (ii) accessibility ( $\mathrm{n}=3$ types) including national and provincial routes, secondary roads, and trails (Fig. 1C); (iii) oil industry ( $\mathrm{n}=3$ types) including oil exploration lines, pipelines, and wells (Fig. 1D and E); and (iv) sheep grazing, representing the potential sheep density in open areas (grasslands and shrublands) (Fig. 1F). This database was constructed using data from the terrestrial information system of Santa Cruz (SIT-Santa Cruz Argentina, http://www.sitsantacr uz.gob.ar), the national energy inventory (http://datos.minem.gob.ar), and sheep density models for the province (Pedrana et al., 2011).

For the next steps, we performed analyses in a geographical information system (GIS), to develop maps for each LIV $(n=11)$. For the second step (B), we need to determine the impact scores from the combination of variables making up the HFI. First, we defined the maximum distance $(\mathrm{km})$ at which each variable was estimated to affect the wilderness character of the land cover (Appendix A in Supplementary Material). To determine this distance, we calculated the mean maximum distance from human settlements at which land cover disturbance can be detected using satellite images (pixels of 1-5 m resolution, working in Google Earth platform). This impact distance was defined as two times the average impact distance detected for each settlement category ( $24.0 \mathrm{~km}$ for capital city, $7.2 \mathrm{~km}$ for other cities, 2.2 $\mathrm{km}$ for small towns, and $2 \mathrm{~km}$ for ranches). For roads, we defined impact distance according to their size and intensity of use, as follows: $2 \mathrm{~km}$ for national routes, $1 \mathrm{~km}$ for provincial routes, and $0.5 \mathrm{~km}$ for secondary roads and trails. These impact distances were mainly based on the potential habitat degradation (e.g. logging, non-timber products, and mineral extraction), exotic species invasion, contamination, hunting or poaching (Bischof, Steyaert, \& Kindberg, 2017; Bullock et al., 2018; Lhoest et al., 2020; Quiroga, Noss, Paviolo, Boaglio, \& Di Bitetti, 2016; Torres, Jaeger, \& Alonso, 2016). The impact distance for oil exploration and pipelines was defined as $0.5 \mathrm{~km}$, considered the size of the infrastructure required for the industry (Entre Nacional Regulador del Gas (ENARGAS), 2016; Dabros, Hammon, Pinzon, Pinno, \& Langor, 2017), as well as the maximum influence distance defined previously for other areas in the world (Pattison, Quinn, Dale, \& Catterall, 2016). The oil wells influence was also defined as $0.5 \mathrm{~km}$, considering the local impact of the facilities (1 ha) and road connectivity (Dabros et al., 2017; Datta et al., 2019; Fuda, Ryan, Cohen, Hartter, \& Frair, 2018). Secondarily, we calculated the impact area of each LIV in the GIS using ArcMap 10.0 software (ESRI, 2011) and Euclidian distance tool, and final grids were rasterized at $90 \times 90 \mathrm{~m}$ resolution using the nearest neighbour resampling technique. Then, for each LIV we re-scaled the grids by a logistic decreasing function through the defined impact distances, e.g. the impact decreased with distance a and had zero influence at the defined maximum distance. The model employed an intercept percent $(\mathrm{Y})$ that defined the decreasing slope. We used $\mathrm{Y}=98$ for human settlements, where higher values decreased slower than lower values; and $\mathrm{Y}=80$ for the other LIVs, where higher and lower values equally decreased. Human population, accessibility, pipelines, wells and other oil facilities were assigned values of impact from 1 (core) to 0 (the maximum impact distance), but oil exploration lines were assigned values of impact from 0 to 0.5 due to potential vegetation recovery (Dabros et al., 2017; Fuda et al., 2018). Finally, we wanted to include a non-traditional variable, sheep grazing impact, and we did so using: (i) the relative probability presence of sheep in the landscape (Pedrana et al., 2011), and (ii) the focal statistic tool in ArcMap 10.0 software. The value for each output cell was a weighted average function of the values of all the input cells, and the specified neighborhood around each pixel location. Then, as described before, we re-scaled the map by the logistic increasing function tool with $Y=80$ (higher and lower values decreased equally), and then used a mask to remove sheep grazing impact inside protected areas and natural forests, because sheep are restricted to open areas. The values of final sheep grazing impact map varied from 0.3 (maximum density) to 0 , since management is based on low-intensity grazing (Oñatibia \& Aguiar, 2016; Pedrana et al., 2011) which was expected to produce a low impact over the natural ecosystems (density varied from 0.2 to 1.6 ewe equivalent.ha ${ }^{-1}$ ) (Peri, Lencinas, Martínez Pastur, Wardell-Johnson, \& Lasagno, 2013).

For the last stage (C), the eleven LIV maps were integrated into a single GIS project with the same projection and a resolution of $90 \times 90$ $\mathrm{m}$. The maximum values for each pixel was extracted for LIV maps using the cell statistics tool in ArcMap 10.0 (ESRI, 2011). The final map of human footprint index (HFI) for the entire Santa Cruz province varied from 0 (without impact) to 1 (maximum impact).

The HFI was analyzed across the landscape through one-way ANOVAs and Tukey post-hoc test. We using a hexagonal binning process to extract the HFI data from the final map, considering two landscape types: (i) ecological areas (Oliva, González, \& Ruial, 2004) using a hexagons of 250,000 ha (Fig. 1G and Appendix B in Supplementary Material), and (ii) the influence of the forest landscape matrix (openlands and forest types) (CIEFAP-MAyDS (Centro de Investigación y Extensión Forestal Andino Patagónico, Ministerio de Ambiente y Desarrollo Sustentable), 2016) (Fig. 1H) using hexagons of 5000 ha. The hexagon sizes were decided according to the studied area (see Appendixes B and D in Supplementary Material). For the ecological areas we analyzed five categories (forest and alpine vegetation, sub-Andean grasslands, dry steppe, shrub-lands and humid steppe), and hexagons were classified according to the highest st pixel values for each category using the cell statistics tool in ArcMap 10.0. For the forest landscape matrix we conducted three different analyses: (i) a first analysis considering three groups of variables including grasslands (G) (grasslands $>70 \%$ ), a mix of grasslands and natural forests (GF) (forest cover between $30 \%$ and $50 \%$ ), and natural forests (F) (forest cover $>50 \%$ ); (ii) a second analysis considering four treatments including grasslands and natural forested areas $>80 \%$ discarding those hexagon with less forest cover, where treatments included pure and mixed forests: G NA (grasslands and Nothofagus antarctica forests), G NP (grasslands and $N$. pumilio forests), G NP-MIX (grasslands and mixed forests of $N$. pumilio and evergreen species), and G NA-NP (grasslands, $N$. antarctica and $N$. pumilio forests); and (iii) a third analysis with the same forest categories as in (ii), but where we excluded grasslands: NA, NP, NP-MIX, and NA-NP (Appendix C and D in Supplementary Material). We also analyzed different degrees of HFI $(<0.3,0.2,0.1$ and 0.05$)$ to identify core areas with more than 1000 and 10,000 ha, We included: (i) the five categories of ecological areas and the protected area network (national parks and provincial reserves) (Fig. 1I), and (ii) the three main forest types presented in the province (Fig. $1 \mathrm{H})$. We also categorized forested core area according its potential biodiversity (for concepts and methodologies see Rosas, Peri, Lencinas et al., 2019). Finally, for each ANOVA, we analysed the autocorrelation across the landscape using the spatial pattern analysis tool in ArcMap 10.0 software (ESRI, 2011), calculating Moran's Index value $(\mathrm{M})$ ( +1.0 indicates clustering while -1.0 indicates dispersion) and a z-score which defines the statistical significance. The null hypothesis for these analyses states that there is no spatial clustering of the values (Bailey \& Gatrell, 1995).

\section{Results}

The HFI showed the human influence on different landscapes of Santa Cruz province (Fig. 2), where the highest impact values (values up to 0.50 ) were located close to the capital city and around main national routes. In the northern areas of Santa Cruz province, oil industry generated a large impact over the landscape (Fig. 1D) (values up to 0.45 close to Cerro Dragón), while intermediate values due to sheep grazing 

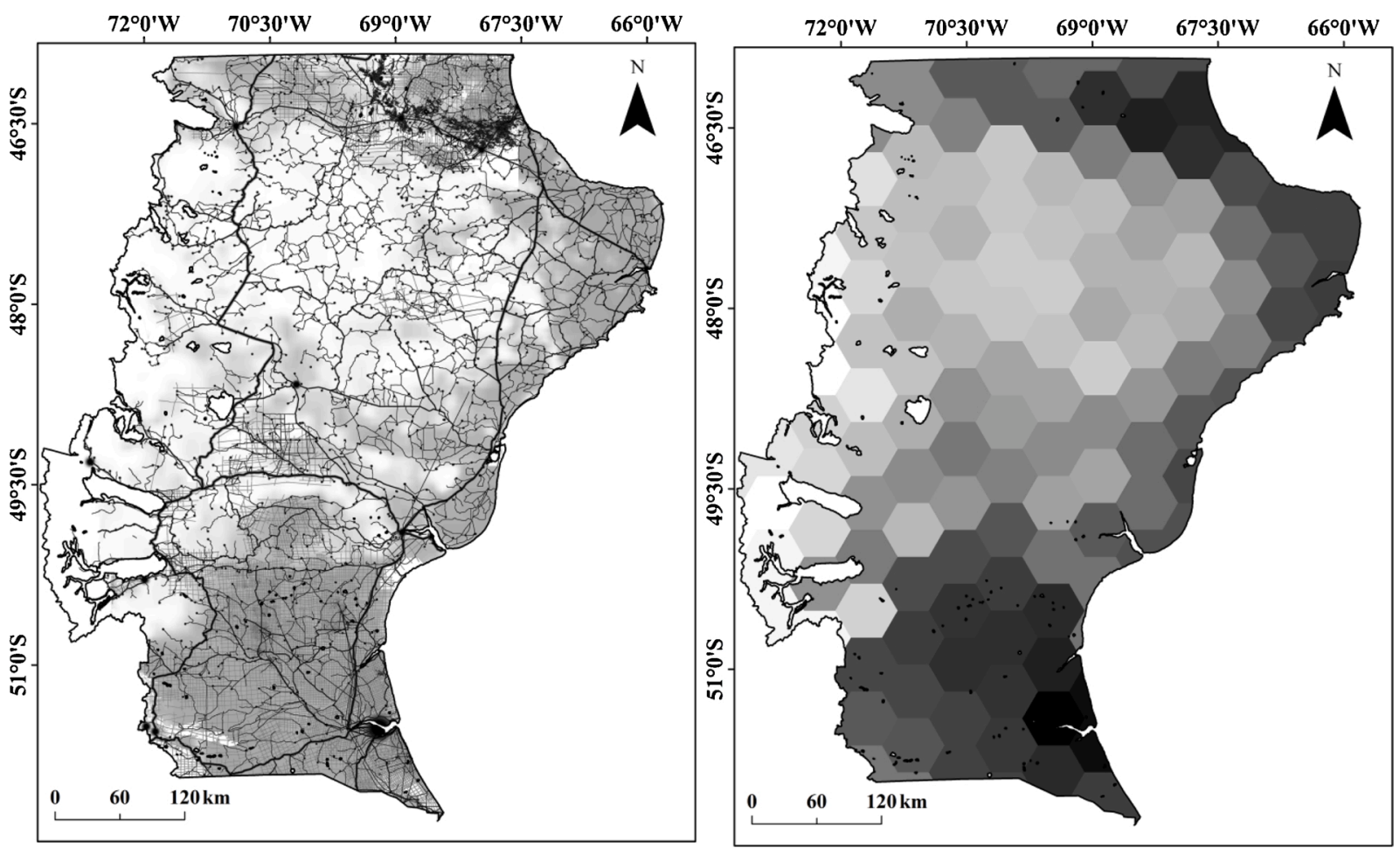

Fig. 2. Map of Human Footprint Index (HFI) of Santa Cruz province (Argentina), where darker color indicates higher values of human impact. The left map depicts $90 \mathrm{~m} \times 90 \mathrm{~m}$ resolution, while the right map shows the average HFI for 250 thousand ha hexagons obtained through the hexagonal binning methodology.

(mean values close to 0.3 ) were located mainly in the south, representing the most important economic activities in the province (Fig. 1E). Finally, the lowest HFI values (near 0.01) were located in the less productive lands of the province (central arid areas) and the west (humid areas near the Andean mountains). The existing infrastructure (routes, trails and ranch facilities) increased the accessibility to remote areas and increased the fragmentation of the landscape.

HFI significantly differed across the landscape $(F=31.50$, Table 1$)$, being lower $(0.07-0.11)$ in areas close to the Andes mountains (forest and alpine vegetation, and sub-Andean grasslands), and higher $(0.38-0.40)$ at southern areas (shrub-lands and humid steppe) close to the capital city. As was expected, ecological areas exhibited significant spatial autocorrelation (Appendix B in Supplementary Material) with M $=0.508$ (z-score $=8.83, \mathrm{p}<0.001)$ that indicated clustering in the extracted hexagons. The HFI also differed according to the forest type and native forest landscapes (Table 2). The landscapes with more forests ( $>50 \%$ forest cover) presented significantly greater HFI values (0.18) than those with lower forest cover $(0.11)(F=6.16)$. The landscapes that combine the presence of forests and grasslands also presented spatial autocorrelation (Appendix DA in Supplementary Material) with $\mathrm{M}=$ 0.437 (z-score $=13.48, \mathrm{p}<0.001$ ) that indicated clustering in the extracted hexagons. Among the forest landscapes, hexagons that combine grasslands and Nothofagus antarctica forests presented higher

Table 1

Results from ANOVA of difference in Human Footprint Index (HFI) among the main ecological areas of Santa Cruz province (Argentina). Different letters denote significant differences among levels.

\begin{tabular}{ll}
\hline Ecological areas & HFI \\
\hline Forest and alpine vegetation & $0.07 \mathrm{a}$ \\
Sub-Andean grasslands & $0.11 \mathrm{a}$ \\
Dry steppe & $0.23 \mathrm{~b}$ \\
Shrub-lands & $0.38 \mathrm{c}$ \\
Humid steppe & $0.40 \mathrm{c}$ \\
$F(p)$ & $31.50(<0.001)$ \\
\hline
\end{tabular}

$\mathrm{F}=$ Fisher test, $(\mathrm{p})=$ probability by Tukey test at 0.05 .
Table 2

ANOVAs of Human Footprint Index (HFI) of Santa Cruz province (Argentina) among different forested landscapes: (i) grasslands and forests, (ii) grasslands and forests types, and (iii) forest types, where: $\mathrm{G}=$ grasslands, $\mathrm{F}=$ forests, $\mathrm{NA}=$ Nothofagus antarctica, $\mathrm{NP}=N$. pumilio, and MIX $=$ mixed evergreen forests.

\begin{tabular}{lll}
\hline Category & Treatments & HFI \\
\hline (i) Grasslands and forests & G & $0.11 \mathrm{a}$ \\
& G + F & $0.11 \mathrm{a}$ \\
& F & $0.18 \mathrm{~b}$ \\
(ii) Forested landscape types & F(p) & $6.16(0.002)$ \\
& G + NP-MIX & $0.04 \mathrm{a}$ \\
& G + NP & $0.04 \mathrm{a}$ \\
& G + NA-NP & $0.18 \mathrm{~b}$ \\
(iii) Forest types & G + NA & $0.34 \mathrm{c}$ \\
& F(p) & $17.43(<0.001)$ \\
& NP-MIX & $<0.01 \mathrm{a}$ \\
& NP & $0.06 \mathrm{a}$ \\
& NA & $0.23 \mathrm{~b}$ \\
& NA-NP & $0.24 \mathrm{~b}$ \\
& F(p) & $13.24(<0.001)$ \\
\hline
\end{tabular}

$\mathrm{F}=$ Fisher test, $(\mathrm{p})=$ probability by Tukey test at 0.05 .

HFI values ( 0.18 and 0.34 for $\mathrm{G}+\mathrm{NA}-\mathrm{NP}$ and $\mathrm{G}+\mathrm{NA}$, respectively) than those without this tree species ( 0.04 for G + NP-MIX and G $+\mathrm{NP})(\mathrm{F}=$ 17.43). In this analysis spatial autocorrelation was lower with $\mathrm{M}=$ 0.152 (z-score $=2.23, \mathrm{p}=0.025$ ) but still indicated clustering in the extracted hexagons. Finally, N. pumilio and evergreen species showed lower HFI values $(<0.01-0.06)$ compared to forest types growing close to the ecotone with the steppe (pure $N$. antarctica forests and their associations with $N$. pumilio forests) that presented higher HFI values $(0.23-0.24)(F=13.24)$. The main forest types did not exhibit show spatial autocorrelation (Appendix DC in Supplementary Material) with $\mathrm{M}=-0.026$ ( $\mathrm{z}$-score $=-0.17, \mathrm{p}=0.857$ ) indicating a random distribution in the extracted hexagons. Spatial autocorrelation analyses showed that some treatments in the ANOVAs are not totally independent and can be influenced by the closeness of the replications. 
Autocorrelation can result in more apparently significant results than the data justify (Dale \& Fortin, 2002). However, these effects decrease when the sample size increases, and in our analyses we employed the full area of each level of the considered treatments.

The HFI was used to characterize the current protected area network in Santa Cruz (Appendix E in Supplementary Material). HFI greatly differed among the different National Parks and Provincial Reserves, mainly related to the previous history, uses, and location in the landscape (Fig. 1I). For example, HFI of national parks varied between 0.02 and 0.19 . The highest index corresponded to the newest national park (e. g. Monte León) created in 2004 which was previously used for sheep production. Provincial reserve HFI values varied between $<0.01$ and 0.79, corresponding to remote areas of Los Andes mountains (e.g. San Lorenzo) and to urban reserves (e.g. Humedal Caleta Olivia), respectively. Beside this, protected areas with native forests had lower HFI values than those located in shrublands and grasslands (for national parks native forest HFI values were $0.03-0.05$ and shrubland and grassland HFI values were $0.10-0.19$, and for provincial reserves $<0.01-0.37$ in forests compared to $0.03-0.79$ in open vegetation).

The current natural reserve network represents $7.0 \%$ of the total provincial area and protects different ecological areas unequally. Protected status ranges from $<0.1 \%$ of total Sub Andean area to $74.5 \%$ for forests and alpine vegetation area (Table 3 ). At the province scale, protected areas as a whole presented a lower HFI $(0.10)$ compared to reserve areas belonging to Dry steppe ecosystems (0.24) and shrublands (0.19), which cover most of Santa Cruz extent. The degree of protection and HFI values (outside and inside the protected areas) of the natural forests were closely related to the ecosystem services that they provide (timber values or silvopastoral uses), e.g. N. antarctica forests with silvopastoral values were less protected (14.2\%) and more highly impacted (HFI of $0.23 \mathrm{o}$ on average and 0.27 in the protected areas) than other forest types ( $N$. pumilio and mixed evergreen forests with timber values) which were protected to a greater extent $(69.8 \%-79.1 \%)$ and less impacted (HFI $0.06-0.09$ on average and $0.05-0.08$ in the protected areas). The conservation of $N$. pumilio and mixed evergreen forests focused on the protection of the areas with greater potential biodiversity (46.6-54.6\% of the highest potential compared to $18.4-20.6 \%$ of the lowest potential are included in the natural reserve

Table 3

Human Footprint Index (HFI) and protected areas network considering ecological areas, forest types (NP $=$ Nothofagus pumilio, NA $=N$. antarctica, and MIX = mixed evergreen forests) and potential biodiversity values (high, medium and low) of the forested landscape areas in Santa Cruz province, Argentina (based on Rosas, Peri, Lencinas et al., 2019).

\begin{tabular}{|c|c|c|c|c|c|}
\hline \multicolumn{3}{|l|}{ Variable } & $\begin{array}{l}\text { Protected } \\
(\%)\end{array}$ & HFI & $\begin{array}{l}\text { HFI within } \\
\text { protected areas }\end{array}$ \\
\hline \multirow[t]{4}{*}{ Total } & & & 7.00 & 0.24 & 0.10 \\
\hline & \multicolumn{2}{|c|}{ Dry steppe } & 2.48 & 0.23 & 0.24 \\
\hline & \multicolumn{2}{|c|}{ Humid steppe } & 0.23 & 0.40 & 0.43 \\
\hline & \multicolumn{2}{|c|}{ Shrub-lands } & 2.26 & 0.38 & 0.19 \\
\hline \multirow[t]{2}{*}{ Ecological areas } & \multicolumn{2}{|c|}{$\begin{array}{l}\text { Sub-Andean } \\
\text { grasslands }\end{array}$} & 0.02 & 0.11 & 0.15 \\
\hline & \multicolumn{2}{|c|}{$\begin{array}{l}\text { alpine } \\
\text { vegetation }\end{array}$} & 74.45 & 0.07 & 0.03 \\
\hline \multirow[t]{3}{*}{ Forests } & \multicolumn{2}{|l|}{ MIX } & 79.10 & 0.09 & 0.08 \\
\hline & \multicolumn{2}{|l|}{ NP } & 69.76 & 0.06 & 0.05 \\
\hline & \multicolumn{2}{|l|}{ NA } & 14.25 & 0.23 & 0.27 \\
\hline \multirow[t]{9}{*}{$\begin{array}{l}\text { Potential } \\
\quad \text { Biodiversity }\end{array}$} & \multirow[t]{3}{*}{ MIX } & High & 54.66 & 0.12 & 0.11 \\
\hline & & Medium & 24.77 & 0.14 & 0.16 \\
\hline & & Low & 20.57 & 0.04 & 0.04 \\
\hline & \multirow[t]{3}{*}{$\mathrm{NP}$} & High & 46.66 & 0.07 & 0.06 \\
\hline & & Medium & 34.92 & 0.05 & 0.04 \\
\hline & & Low & 18.42 & 0.05 & 0.05 \\
\hline & \multirow[t]{3}{*}{ NA } & High & 18.78 & 0.23 & 0.26 \\
\hline & & Medium & 28.03 & 0.21 & 0.31 \\
\hline & & Low & 53.18 & 0.21 & 0.28 \\
\hline
\end{tabular}

network), but these areas had greater HFI values due to the past uses prior to their designation as parks and reserves (low potential biodiversity areas exhibited lower HFI, for both forest types) (Table 3). In contrast, for $N$. antarctica forests, the lowest potential biodiversity sites were more protected (53.2\%) due to the trade-offs with ranching activities. Beside this, the potential biodiversity qualities of the forests presented similar HFI $(0.21-0.23$ on average and $0.26-0.31$ in the protected area network).

Considering these strengths and trade-offs of the current protected area network, we used the HFI and the fragmentation that produce this index (Appendixs E and F in Supplementary Material) in the landscape to identify potential conservation areas by patch size for the natural forests (e.g. potential biodiversity). We focused our analysis on polygons of $>1000$ and $>10,000$ ha with different HFI thresholds (less than 0.05 to 0.3 ) (Table 4). The most restrictive scenario identified 115 polygons with $<0.05$ HFI mainly located in the dry steppe $(n=100)$, and just one in the most threatened ecological areas (e.g. humid steppe) or forest types (e.g. N. antarctica located near to Monte Zeballos with low values of potential biodiversity). When HFI index was combined with other variables (e.g. potential biodiversity), the identification of potential areas become more restrictive. For mixed evergreen forests we identified just one polygon of 1300 ha with $<0.05$ HFI and medium potential biodiversity value. For $N$. pumilio forests we found major availability of different sizes and potential biodiversity qualities, which decreased when polygon size became larger. Finally, as previously mentioned previously, we identified large polygons ( $>10,000$ ha) of low biodiversity value in $N$. antarctica forests. However, if we consider smaller polygons ( $>1000 \mathrm{ha}$ ) we found more forests with higher potential biodiversity values across the different analysed HFI indexes.

\section{Discussion}

Reduction and fragmentation of ecosystems due to human activities is the main cause of biodiversity and ecosystem service losses (Jacobson et al., 2019), with great spatial and temporal variation (Venter et al., 2016). Human activities are continuously expanding at a global scale, affecting the remaining natural ecosystems in remote areas, such as Southern Patagonia. Extensive livestock production, forest harvest, and tourism are advancing in formerly undisturbed areas, but we lack of information on the spatial and intensity effect of these impacts on ecosystems to support conservation decision making (Inostroza et al., 2016). One alternative to solve this problem is to analyze spatially the human impact at the landscape level (Sanderson et al., 2002; Venter et al., 2016).

We developed a HFI map for Santa Cruz province that improved on the one previously developed based on worldwide data (e.g. Sanderson et al., 2002). Our HFI map at regional scale is useful for many purposes (e.g. land-use planning or developing conservation strategies at landscape level), as has been proposed for other regions, e.g. for water retention and biodiversity conservation values on the Tibetan Plateau (Li et al., 2018), and habitat connectivity in Mexico (Correa Ayram et al., 2017). This is consistent with Li et al. (2018) and Guzmán Colón, Pidgeon, Martinuzzi, and Radeloff (2020)) who stated that the global scale datasets are not well suited for regional analyses because most of the proposals at larger scales are based on remote sensing data. However, at local or regional scales itis is possible to include more diverse and specific data related to direct and indirect human impacts (see Appendix A in Supplementary Material). The selection of variables is a critical factor in development of the HFI (Anderson \& Mammides, 2020; Inostroza et al., 2016; Li et al., 2018; Martin, Green, \& Balmford, 2019; Venter et al., 2016). We suggest that the inclusion of different local impacts had been successful, e.g. while sheep grazing was the most important driver of the HFI at landscape level in southern Patagonia (Pedrana et al., 2011; Peri et al., 2013), drivers in other regions were poaching, illegal harvesting or human settlements (e.g. Fiori \& Zalba, 2003; Hulme, 2018; Anderson \& Mammides, 2020). Grazing density was 
Table 4

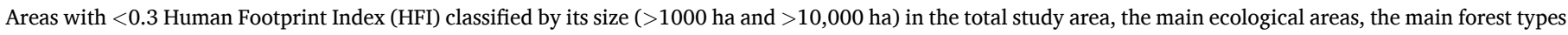

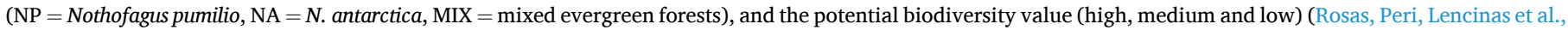

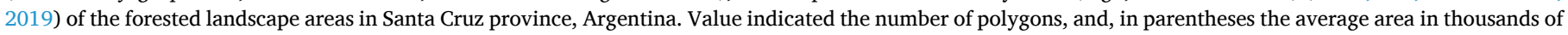
ha.

\begin{tabular}{|c|c|c|c|c|c|c|c|c|c|c|}
\hline \multirow{3}{*}{ Variable } & & & \multicolumn{4}{|c|}{ Potential natural protected areas networking } & & & & \\
\hline & & & \multicolumn{4}{|c|}{ HFI for 1000 ha polygons } & \multicolumn{4}{|c|}{ HFI for 10,000 ha polygons } \\
\hline & & & $<0.3$ & $<0.2$ & $<0.1$ & $<0.05$ & $<0.3$ & $<0.2$ & $<0.1$ & $<0.05$ \\
\hline \multirow[t]{3}{*}{ Total } & & & $1,765(163.0)$ & $1,092(144.5)$ & $758(124.0)$ & $488(10.0)$ & $281(389.1)$ & $205(320.0)$ & $156(251.3)$ & $115(480.2)$ \\
\hline & Dry s & ppe & $1,246(32.0)$ & $921(25.0)$ & $647(18.0)$ & $419(12.0)$ & $243(108.0)$ & $176(88.0)$ & $134(59.5)$ & $100(39.0)$ \\
\hline & Hum & steppe & $181(5.0)$ & $3(2.4)$ & 0 & 0 & $3(20.4)$ & 0 & 0 & 0 \\
\hline \multirow{4}{*}{ Ecological areas } & Shrul & lands & $192(23.3)$ & $32(21.1)$ & $10(15.3)$ & $6(5.4)$ & $10(90.4)$ & $5(74.0)$ & $2(49.1)$ & $1(16.4)$ \\
\hline & Sub- & dean grasslands & $99(57.0)$ & $94(52.0)$ & $65(48.0)$ & $31(40.4)$ & $21(170.3)$ & $20(158.4)$ & $16(142.6)$ & $10(118.0)$ \\
\hline & $\begin{array}{l}\text { Fores } \\
\text { veget }\end{array}$ & $\begin{array}{l}\text { and alpine } \\
\text { tion }\end{array}$ & $47(46.0)$ & $42(45.0)$ & $36(43.0)$ & $32(41.0)$ & 0 & 0 & 0 & $4(307.0)$ \\
\hline & MIX & & 0 & 0 & 0 & $1(1.3)$ & 0 & 0 & 0 & 0 \\
\hline \multirow[t]{6}{*}{ Forests } & $\mathrm{NP}$ & & 34 (91.1) & 31 (89.5) & $26(88.0)$ & $22(85.0)$ & 0 & 0 & 0 & $9(201.0)$ \\
\hline & NA & & $46(35.0)$ & $31(30.2)$ & $22(21.0)$ & $21(18.4)$ & $4(409.1)$ & $3(378.0)$ & $1(343.0)$ & $1(343.0)$ \\
\hline & & High & 0 & 0 & 0 & 0 & 0 & 0 & 0 & 0 \\
\hline & MIX & Medium & 0 & 0 & 0 & $1(1.3)$ & 0 & 0 & 0 & 0 \\
\hline & & Low & 0 & 0 & 0 & 0 & 0 & 0 & 0 & 0 \\
\hline & & High & $10(37.1)$ & $8(36.0)$ & $8(36.0)$ & $6(34.0)$ & 0 & 0 & 0 & $1(176.3)$ \\
\hline \multirow[t]{5}{*}{ Potential Biodiversity } & NP & Medium & $12(54.0)$ & $11(52.0)$ & $11(52.0)$ & $9(48.1)$ & 0 & 0 & 0 & $4(104.0)$ \\
\hline & & Low & $12(178.0)$ & $12(178.0)$ & $7(176.0)$ & $7(176.0)$ & 0 & 0 & 0 & $4(304.1)$ \\
\hline & & High & $13(15.0)$ & $10(3.1)$ & $9(2.1)$ & $9(2,046)$ & $1(31.1)$ & 0 & 0 & 0 \\
\hline & NA & Medium & $6(5.0)$ & $3(2.0)$ & $3(2.0)$ & $3(2.0)$ & 0 & 0 & 0 & 0 \\
\hline & & Low & $27(56.0)$ & $18(53.1)$ & $10(43.0)$ & $9(40.3)$ & $3(378.0)$ & $3(378.0)$ & $1(343.0)$ & $1(343.0)$ \\
\hline
\end{tabular}

previously proposed as a variable in the HFI estimation for Li et al. (2018), being the major anthropogenic disturbance at regional level in the Tibetan Plateau. Another variable of significant importance for Southern Patagonia was oil exploration and exploitation, which greatly influenced biodiversity. Fiori and Zalba (2003) determined that vegetation recovery on seismic lines is extremely poor, and acts as a barrier for many native species, while providing access points for poaching and for expansion of exotic invasive plants.

Anderson and Mammides (2020) found a greater overall increase in HFI in tropical than temperate regions. In our study area, located in a temperate-cold region, the higher localized impacts ( $>0.5$ of HFI) were related to: (i) proximity to big cities, (ii) major infrastructure (e.g. national roads) that provide accessibility, and (iii) extractive industries (e. g. oil wells). This concurs with findings in Central Africa when comparing settlement proximity and management impact with conservation of tropical forests (Lhoest et al., 2020), oil extraction and mammal conservation in Uganda (Fuda et al., 2018), road network influence in China (Liu et al., 2008) and northern Argentina (Martinuzzi et al., 2018), and rural settlements and biodiversity in Argentina (Macchi \& Grau, 2012). Generally, the HFI impacts were positively related to ecosystem productivity (e.g. net primary productivity) (e.g. see Rosas et al., 2018, 2019a; Peri, Rosas et al., 2019) where most sheep ranching and forestry activities were conducted (e.g. see Peri et al., 2013), and most infrastructure has been established. The inclusion of sheep grazing intensity allowed better representation of this impact at landscape level than presence/absence would have. Thus, the lowest HFI values $(<0.1$ of $\mathrm{HFI}$ ) were occurred in marginal ecosystems with low productivity (e.g. dry steppe grasslands) or in rough terrain or mountain regions (e.g. naturally inaccessible forests in the upper basins). As has been found in other studies, human impact was related to human density, economic profit potential and accessibility (Buckley, Zhou, \& Zhong, 2016; Inostroza et al., 2016; Venter et al., 2016).

A similar trend was observed for different forest types, where HFI was positively related to the economic potential of the forest species. For example, $N$. antarctica exhibited greater impact (high HFI value) because it is commonly used for silvopastoral and sheep grazing regardless of site quality or forest productivity. Sheep production is the most economically profitable and most traditional livelihood in Southern Patagonia (Peri et al., 2013). Timber harvests focused on $N$. pumilio forests, which in consequence had greater HFI values than mixed evergreen forests that traditionally were excluded from forest extraction activities due to low timber quality and accessibility (Peri, Monelos et al., 2019). The landscape diversity where these forest types occurred also influenced HFI values, in that human impact was higher where the landscape was more diverse. Diverse landscapes are more productive and can support more human economic activities, and thus we had expected a greater human impact compared to more simple natural landscapes (e.g. this consideration was not true in urban and peri-urban landscapes). However, little research has been published on this topic. The exact consequences of human influence in any given location are complicated, however, and depend on the history of the place, the types of the current influence, and the parts of nature that we are concerned with (Redford \& Richter, 1999; Sanderson et al., 2002). We believe that this effect was due to higher human activities in diverse landscapes (e.g. uses with an array of economic oportunities including forest harvesting, ranching, tourism, recreation, etc.) (Martínez Pastur et al., 2016).

The HFI was proposed as a tool to identify the wilderness status of a particular area (Anderson \& Mammides, 2020; Sanderson et al., 2002) for identifying potential conservation locations. This is based on the concept that human uses decrease the conservation values of natural ecosystems (e.g. Venter et al., 2016; Di Marco et al., 2018; Li et al., 2018). For this, wildest places offer the greatest opportunities to conserve the full range of nature that still exists (Sanderson et al., 2002). The HFI has been used for different purposes for decision making (e.g. to identify factors influencing mammal and reptile mortality, water retention, to characterize natural parks, improve existing land-use plans, or define potential species ranges) (Buckley et al., 2016; Li et al., 2018; Photopoulou, 2018; Martinuzzi et al., 2018; Hill, De Vault, \& Belant, 2019; Hill, De Vault, Wang, \& Belant, 2020). In this paper, we used the HFI to characterize the protected area network (National Parks and Provincial Reserves) of the study region. While Anderson and Mammides (2020) found an increase of HFI outside protected areas, Buckley et al. (2016) found that less populated areas (located in extreme climate areas) were associated with low HFI. In our study area, protected areas located near cities had the highest HFI values (e.g. urban reserves), as did newly created reserves (e.g. Monte Leon National Park) which had other purposes in the past (e.g. ranching). However, the potential of this tool is not only the ability to characterize the current network, but also identification of new areas for conservation. Furthermore, we propose that intersecting HFI with indices of landscape fragmentation based on 
the concept of the last of the wild (Sanderson et al., 2002), like the size of the intact patches, and the representativeness of the ecosystems in the natural reserve network, leads to important insights about conservation potential. Using these three variables, we identified patches with high conservation potential values that depend on forest types according to their potential economic values and historical uses (Peri et al., 2013, 2019b, 2019a). For example, while use of the small patch threshold (e.g. $>1000 \mathrm{ha}$ ) was more effective in detecting potential areas in more impacted forest types, analysis of large patches (e.g. > 10,000 ha) was more effective in detecting potential areas in more abundant and less impacted forest types.

Finally, it is important to highlight that the HFI is highly compatible with other land-use management decision making tools that actually were implemented in Patagonia Argentina, e.g. ordination processes for the sustainable management and conservation of the native forests (see Martínez Pastur et al., 2020). This simple methodology can be useful for those responsible of planning that are land use planners looking for a complement to existing tools rather than requiring a radical rethink of how conservation planning or management is approached.

\section{Conclusions}

Worldwide landscapes are being changed substantially due to human impacts, and we need ways to understand and measure how human pressures evolve in the framework of different management and conservation planning. The methodology presented here can help provide similar spatial assessments in other remote areas by downscaling global assessments and improve policy measures for the conservation of the last remaining undisturbed natural areas. HFI is a powerful tool that in combination with other tools (e.g. potential biodiversity maps) can provide relevant information to those who make national or regional policy decisions. The development of HFI maps allows simplifying different sources of information about human impact, generating a powerful tool for decision-making. The HFI map developed in this study can be used to: (i) support assessment of ecological and biogeographic changes in species, and in different ecosystem models to assess humancaused ecosystem services and biodiversity losses; (ii) identify potential trade-offs between economic activities (e.g. livestock, harvesting) and conservation; and (iii) understand the potential risks of different infrastructure development proposals on natural ecosystems. The HFI also can contribute to define new management planning at landscape level, or as an indicator to determine the effectiveness of conservation projects on time. However, inclusion of more human stressors in the HFI will improve the index and better reflect the cumulative effects of the human impacts in natural ecosystems.

The HFI represents an opportunity to detect and monitor human influence at fine spatial scales, which may have heretofore remained unnoticed. Because such alterations are becoming more frequent in remote regions as Southern Patagonia, the assessment approaches presented here provide important information on human-environment interactions to support land-use and nature conservation policy design. In addition, fine-scale analyses and different types of economic activities are considered to support policies that can protect the remaining natural areas from human encroachment. Collectively, these findings highlight shifts in anthropogenic disturbance sources as the human footprint changes, and will require more specific studies for the different variables and forest-type specific conservation strategies as landscapes become increasingly disturbed by anthropogenic activities. Government must include the concept of intact wild areas in their prioritization schemes, to increase the effectiveness of management (e.g. oil, grazing, forestry) and conservation strategies, since the drivers of human pressures extend to most territories, including those relatively remote inhabited areas such as Southern Patagonia. Looking forward, it will be increasingly necessary to accommodate the development of human economic activities inplanning of ecologically important landscapes, and the HFI provides one easy-to-implement option for accomplishing this.

\section{Declaration of Competing Interest}

The authors declare that they have no competing interests.

\section{Acknowledgements}

ToWe thank Sebastián Martinuzzi, for very useful comments. We thank Consejo Agrario Provincial of Santa Cruz Province for support. Support was also provided by NASA (Grant number18-SLSCVC18-0019) This research is part of the doctoral thesis of YMR (Faculty of Ciencias Agrarias y Forestales in the Universidad Nacional de la Plata).

\section{Appendix A. Supplementary data}

Supplementary material related to this article can be found, in the online version, at doi:https://doi.org/10.1016/j.jnc.2020.125946.

\section{References}

Anderson, E., \& Mammides, C. (2020). The role of protected areas in mitigating human impact in the world's last wilderness areas. Ambio, 49(2), 434-441.

Bailey, T. C., \& Gatrell, A. C. (1995). Interactive spatial data analysis. Harlow, England: Addison Wesley Longman Ld.

Baldwin, R. F., Powell, R. B., \& Kellert, S. R. (2011). Habitat as architecture: Integrating conservation planning and human health. Ambio, 40, 322-327.

Bischof, R., Steyaert, S., \& Kindberg, J. (2017). Caught in the mesh: Roads and their network-scale impediment to animal movement. Ecography, 40(12), 1369-1380.

Buckley, R., Zhou, R., \& Zhong, L. (2016). How pristine are China's parks? Frontiers in Ecology and Evolution, 4, e136.

Bullock, J. M., Bonte, D., Pufal, G., da Silva Carvalho, C., Chapman, D. S., García, C., Mar Delgado, M. (2018). Human-mediated dispersal and the rewiring of spatial networks. Trends in Ecology \& Evolution, 33, 958-970.

Burton, A. C., Huggard, D., Bayne, E., Schieck, J., Sólymos, P., Muhly, T., ... Boutin, S. (2014). A framework for adaptive monitoring of the cumulative effects of human footprint on biodiversity. Environmental Monitoring and Assessment, 186, 3605-3617.

CIEFAP-MAyDS (Centro de Investigación y Extensión Forestal Andino Patagónico, Ministerio de Ambiente y Desarrollo Sustentable). (2016). Actualización de la Clasificación de Tipos Forestales y Cobertura del Suelo de la Región Bosque Andino Patagónico. Informe Final. Buenos Aires, Argentina.

Corlett, R. T. (2015). The Anthropocene concept in ecology and conservation. Trends in Ecology \& Evolution, 30(1), 36-41.

Correa Ayram, C. A., Mendoza, M. E., Etter, A., \& Perez Salicrup, D. R. (2017), Anthropogenic impact on habitat connectivity: A multidimensional human footprint index evaluated in a highly biodiverse landscape of Mexico. Ecology and Industry of Russia, 72, 895-909.

Costanza, R., De Groot, R., Braat, L., Kubiszewski, I., Fioramonti, L., Sutton, P., Grasso, M. (2017). Twenty years of ecosystem services: How far have we come and how far do we still need to go? Ecosystem Services, 28(A), 1-16.

Dabros, A., Hammon, H. E. J., Pinzon, J., Pinno, B., \& Langor, D. (2017). Edge influence of low-impact seismic lines for oil exploration on upland forest vegetation in northern Alberta (Canada). Forest Ecology and Management, 400(15), 278-288.

Dale, M., \& Fortin, M. J. (2002). Spatial autocorrelation and statistical tests in ecology. Écoscience, 9(2), 162-167.

Datta, S., Rahman, S., Borhan, S., Saini-Eidukat, B., Cihacek, L., \& Ringwall, K. (2019). Quantification and characterization of particulate matter generated from unpaved roads in the oil development area of western North Dakota. Transactions of the ASABE, 62(3), 615-625.

de Groot, R., Brander, L., Van Der Ploeg, S., Costanza, R., Bernard, F., Braat, L., ... Van Beukeringh, P. (2012). Global estimates of the value of ecosystems and their services in monetary units. Ecosystem Service, 1, 50-61.

Di Marco, M., Venter, O., Possingham, H. P., \& Watson, J. E. (2018). Changes in human footprint drive changes in species extinction risk. Nature Communications, 9, e4621.

Entre Nacional Regulador del Gas (ENARGAS). (2016). Normas argentinas mínimas de seguridad para el transporte y distribución de gas natural y otros gases por cañería. NAG100. Buenos Aires, Argentina.

ESRI. (2011). ArcGIS desktop: Release 10. Redlands, USA: Environmental Systems Research Institute Inc.

Fiori, S. M., \& Zalba, S. M. (2003). Potential impacts of petroleum exploration and exploitation on biodiversity in a Patagonian Nature Reserve, Argentina. Biodiversity and Conservation, 12, 1261-1270.

Fuda, R. K., Ryan, S. J., Cohen, J. B., Hartter, J., \& Frair, J. L. (2018). Assessing the impacts of oil exploration and restoration on mammals in Murchison Falls conservation area, Uganda. African Journal of Ecology, 56(4), 804-817.

Guzmán Colón, D. K., Pidgeon, A. M., Martinuzzi, S., \& Radeloff, V. C. (2020). Conservation planning for island nations: Using a network analysis model to find novel opportunities for landscape connectivity in Puerto Rico. Global Ecology and Conservation, Article e01075 (in press).

Hansen, M. C., Potapov, P. V., Moore, R., Hancher, M., Turubanova, S. A., Tyukavina, A., Townshend, J. R. (2013). High-resolution global maps of 21st-century forest cover change. Science, 342, 850-853. 
Hill, J. E., De Vault, T., \& Belant, J. (2019). Impact of the human footprint on anthropogenic mortality of North American reptiles. Acta Oecologica, 101, Article e103486.

Hill, J. E., De Vault, T., Wang, G., \& Belant, J. (2020). Anthropogenic mortality in mammals increases with human footprint. Frontiers in Ecology and the Environment, 18(1), 13-18.

Hulme, P. E. (2018). Protected land: Threat of invasive species. Science, 361, 561-562.

Inostroza, L., Zasada, I., \& König, H. J. (2016). Last of the wild revisited: Assessing spatial patterns of human impact on landscapes in Southern Patagonia, Chile. Regional Environmental Change, 16(7), 2071-2085.

Jacobson, A. P., Riggio, J., Tait, A. M., \& Baillie, J. E. (2019). Global areas of low human impact ('Low Impact Areas') and fragmentation of the natural world. Scientific Reports, 9, Article e14179.

Lhoest, S., Fonteyn, D., Daïnou, K., Delbeke, L., Doucet, J. L., Dufrêne, M., ... Fayolle, A. (2020). Conservation value of tropical forests: Distance to human settlements matters more than management in Central Africa. Biological Conservation, 241, Article e108351.

Li, S., Zhang, Y., Wang, Z., \& Li, L. (2018). Mapping human influence intensity in the Tibetan Plateau for conservation of ecological service functions. Ecosystem Service, 30, 276-286.

Liu, S., Cui, B. S., Dong, S. K., Yang, Z. F., Yang, M., \& Holt, K. (2008). Evaluating the influence of road networks on landscape and regional ecological risk: A case study in Lancang River Valley of Southwest China. Ecological Engineering, 34(2), 91-99.

Loveland, T. R., Reed, B. C., Brown, J. F., Ohlen, D. O., Zhu, J., Yang, L., Merchant, J. W. (2000). Development of a global land cover characteristics database and IGBP DISCover from 1-km AVHRR data. International Journal of Remote Sensing, $21,1303-1330$.

Macchi, L., \& Grau, H. R. (2012). Piospheres in the dry Chaco: Contrasting effects of livestock puestos on forest vegetation and bird communities. Journal of Arid Environments, 87, 176-187.

Mace, G. M., Balmford, A., \& Ginsberg, J. R. (1998). Conservation in a changing world. Cambridge, UK: Cambridge University Press.

Martin, P. A., Green, R. E., \& Balmford, A. (2019). Is biodiversity as intact as we think is? PeerJ, 7, Article e27575.

Martínez Pastur, G., Peri, P. L., Lencinas, M. V., García Llorente, M., \& Martín López, B. (2016). Spatial patterns of cultural ecosystem services provision in Southern Patagonia. Landscape Ecology, 31, 383-399.

Martínez Pastur, G., Schlichter, T., Matteucci, S. D., Gowda, J. H., Huertas Herrera, A., Toro Manríquez, M., Lencinas, M. V., Cellini, J. M., \& Peri, P. L. (2020). Synergies and trade-offs of national conservation policy and agro-forestry management over forest loss in Argentina during the last decade. En: Latin America in times of global environmental change. In C. Lorenzo (Ed.), The Latin American studies book series (pp. 135-155). Cham, Switzerland: Springer.

Martinuzzi, S., Rivera, L., Politi, N., Bateman, B. L., Ruiz de los Llanos, E., Lizarraga, L., ... Radeloff, V. C. (2018). Enhancing biodiversity conservation in existing land-use plans with widely available datasets and spatial analysis techniques. Environmental Conservation, 45(3), 252-260.

McGowan, P. J. (2016). Mapping the terrestrial human footprint. Nature, 537, 172-173.

Myers, N., Mittermeier, R. A., Mittermeier, C. G., Da Fonseca, G., \& Kent, J. (2000). Biodiversity hotspots for conservation priorities. Nature, 403, 853-858.

Oliva, G., González, L., \& Ruial, P. (2004). Áreas ecológicas. Guía Geográfica Interactiva de Santa Cruz (pp. 14-15). Ed. INTA. Buenos Aires, Argentina.

Oñatibia, G. R., \& Aguiar, M. R. (2016). Continuous moderate grazing management promotes biomass production in Patagonian arid rangelands. Journal of Arid Environments, 125, 73-79.
Pattison, C. A., Quinn, M. S., Dale, P., \& Catterall, C. P. (2016). The landscape impact of linear seismic clearings for oil and gas development in boreal forest. Northwest Science, 90(3), 340-354.

Pedrana, J., Bustamante, J., Rodríguez, A., \& Travaini, A. (2011). Primary productivity and anthropogenic disturbance as determinants of Upland Goose Chloephaga picta distribution in southern Patagonia. IBIS, 153, 517-530.

Peri, P. L., Lencinas, M. V., Martínez Pastur, G., Wardell-Johnson, G. W., \& Lasagno, R. (2013). Diversity patterns in the steppe of Argentinean Southern patagonia: Environmental drivers and impact of grazing. In M. B. Morales Prieto, \& J. Traba Díaz (Eds.), Steppe ecosystems: Biological diversity, management and restoration (pp. 73-95). New York, USA: NOVA Science Publishers.

Peri, P. L., Lencinas, M. V., Bousson, J., Lasagno, R., Soler, R., Bahamonde, H., Martinez Pastur, G. (2016). Biodiversity and ecological long-term plots in Southern Patagonia to support sustainable land management: The case of PEBANPA Network. Journal for Nature Conservation, 34, 51-64.

Peri, P. L., Monelos, L., Díaz, B., Mattenet, F., Huertas, L., Bahamonde, H., ... Martínez Pastur, G. (2019). Estado y usos de los bosques nativos de lenga, siempreverdes y mixtos en Santa Cruz: Base para su conservación y manejo. Ed. INTA. Buenos Aires, Argentina.

Peri, P. L., Rosas, Y. M., Ladd, B., Toledo, S., Lasagno, R. G., \& Martínez Pastur, G. (2019). Modelling soil nitrogen content in South Patagonia across a climate gradient, vegetation type, and grazing. Sustainability, 11, e2707.

Pertierra, L. R., Hughes, K. A., Vega, G. C., \& Olalla-Tárraga, M. A. (2017). High resolution spatial mapping of human footprint across Antarctica and its implications for the strategic conservation of avifauna. PloS One, 12(1), Article e0168280.

Photopoulou, T. (2018). Human footprint restricts ranges. Nature Ecology \& Evolution, 2 (5), 773-774.

Quiroga, V. A., Noss, A. J., Paviolo, A., Boaglio, G. I., \& Di Bitetti, M. (2016). Puma density, habitat use and conflict with humans in the Argentine Chaco. Journal for Nature Conservation, 31, 9-15.

Redford, K. H., \& Richter, B. D. (1999). Conservation of biodiversity in a world of use. Conservation Biology, 13, 1246-1256.

Rosas, Y. M., Peri, P. L., \& Martínez Pastur, G. (2018). Potential biodiversity map of lizard species in Southern Patagonia: Environmental characterization, desertification influence and analyses of protection areas. Amphibia-Reptilia, 39, 289-301.

Rosas, Y. M., Peri, P. L., Carrara, R., Flores, G., Pedrana, J., \& Martínez Pastur, G. (2019). Potential biodiversity map of darkling beetles (Tenebrionidae): Environmental characterization, land-uses and analyses of protection areas in Southern Patagonia. Journal of the Institute of Conservation, 23, 885-897.

Rosas, Y. M., Peri, P. L., Lencinas, M. V., \& Martínez Pastur, G. (2019). Potential biodiversity map of understory plants for Nothofagus forests in Southern Patagonia: Analyses of landscape, ecological niche and conservation values. Science of the Total Environment, 682, 301-309.

Sanderson, E. W., Jaiteh, M., Levy, M. A., Redford, K. H., Wannebo, A. V., \& Woolmer, G. (2002). The human footprint and the last of the wild. BioScience, 52(10), 891-904.

Torres, A., Jaeger, J. A., \& Alonso, J. C. (2016). Assessing large-scale wildlife responses to human infrastructure development. PNAS, 113(30), 8472-8477.

Venter, O., Sanderson, E. W., Magrach, A., Allan, J. R., Beher, J., Jones, K. R., .. Watson, J. (2016). Sixteen years of change in the global terrestrial human footprint and implications for biodiversity conservation. Nature Communications, 7, Article e12558.

Watson, J., Shanahan, D. F., Di Marco, M., Allan, J., Laurance, W. F., Sanderson, E., Venter, O. (2016). Catastrophic declines in wilderness areas undermine global environment targets. Current Biology, 26, 2929-2934.

Woolmer, G., Trombulak, S. C., Ray, J. C., Doran, P. J., Anderson, M. G., Baldwin, R. F., Sanderson, E. W. (2008). Rescaling the Human Footprint: A tool for conservation planning at an ecoregional scale. Landscape and Urban Planning, 87(1), 42-53. 